\title{
CHANGES IN TYMPANIC TEMPERATURE DURING THE EXPOSURE TO ELECTROMAGNETIC FIELDS EMITTED BY MOBILE PHONE
}

ALICJA BORTKIEWICZ ${ }^{1}$, ELŻBIETA GADZICKA ${ }^{1}$, WIESŁAW SZYMCZAK ${ }^{2}$, and MAREK ZMYŚLONY ${ }^{3}$

${ }^{1}$ Nofer Institute of Occupational Medicine, Łódź, Poland

Department of Work Physiology and Ergonomics

${ }^{2}$ University of Łódź, Łódź, Poland

Department of Psychological Research Methodology and Statistics

${ }^{3}$ Nofer Institute of Occupational Medicine, Łódź, Poland

Department of Radiation Protection

\begin{abstract}
Objective: Mobile phones generate microwave radiation which is absorbed by exposed tissue and converted into heat. It may cause detrimental health effects. The aim of the experiment was to check if exposure to EMF emitted by mobile phone influenced the tympanic temperature. Material and Methods: Human volunteer study was performed on ten healthy young men, aged $22.1 \pm 4.7$ years, examined three times: 1 . on a day with $2 \times 60 \mathrm{~min}$ of no exposure (sham day), 2 . on a day with continuous, $60 \mathrm{~min}$ exposure and $60 \mathrm{~min}$ of no exposure, 3 . on a day with intermittent exposure (4x 15 min "on" and $4 \times 15$ min "off"). Exposure was generated by mobile phone (frequency $900 \mathrm{MHz}$, SAR $1.23 \mathrm{~W} / \mathrm{kg}$ ). The study was double-blind, performed under controlled conditions (at $24^{\circ} \mathrm{C}$ and $70 \%$ humidity). The tympanic temperature $\left(\mathrm{T}_{\text {ty }}\right)$ was monitored every $10 \mathrm{sec}$ by a thermistor probe placed close to the aural canal membrane in the ear opposite the one in contact with mobile phone (contralateral position). Multivariate repeated-measures analysis of variance was used to calculate the results. Results: The mean $\mathrm{T}_{\mathrm{ty}}$ in the whole group during continuous exposure was significantly higher than during sham exposure $(\mathrm{p}=0.0001)$. During intermittent exposure the temperature was lower than during sham day (difference was up to $0.11^{\circ} \mathrm{C}$ ). Within an hour after continuous exposure, $\mathrm{T}_{\text {ty }}$ was higher by $0.03^{\circ} \mathrm{C}$ and after intermittent exposure $\mathrm{T}_{\text {ty }}$ was lower by $0.18^{\circ} \mathrm{C}$ in comparison with sham day. Two hours after exposure $\mathrm{T}_{\text {ty }}$ was significantly lower $(\mathrm{p}=0.0001)$ than after sham exposure $\left(0.06^{\circ} \mathrm{C}\right.$ and $0.26^{\circ} \mathrm{C}$ respectively). The trends in $\mathrm{T}_{\mathrm{ty}}$ during experiment differed significantly in relation to exposure conditions $(\mathrm{p}<0.05)$. Conclusions: The results of this analysis indicate that the physiological response to EMF exposure from mobile phone was mostly related to type of exposure (continuous or intermittent).
\end{abstract}

Key words:

Radiofrequency radiation, Microwave radiation, Thermoregulation, Physiological reaction to electromagnetic fields

This study was supported by the National Committee for Scientific Research (KBN) in Poland.

Received: October 10, 2010. Accepted: January 11, 2011.

Address reprint request to A. Bortkiewicz, Department of Work Physiology and Ergonomics, Nofer Institute of Occupational Medicine, św. Teresy 8, 91-348 Łódź, Poland (e-mail:alab@sunlib.p.lodz.pl). 


\section{INTRODUCTION}

Mobile phones have been in use since 1983, and the recent decade has seen their quick proliferation. Their widespread use has caused that there has been a growing interest in the effect of electromagnetic fields (EMF) generated by the phones on the human organism [1]. Some reports indicate that the use of mobile phones may lead to a number of symptoms, such as headache, impaired concentration and memory, fatigue, sleep and neurovegetative disorders [2].

The radiofrequency electromagnetic fields penetrate exposed tissues, which absorb EMF energy. This energy is converted thereafter into heat [3]. The parameter used for assessment of the absorbed EMF energy is the specific absorption rate (SAR) that can be averaged over the whole body or a particular organ or tissue [4].

For hand-held radiotelephones used by the general public, International Commission on Non-Ionizing Radiation Protection has decided that the localized SAR in the head be limited to $2 \mathrm{~W} / \mathrm{kg}$ averaged on over $10 \mathrm{~g}$ tissue and this means that the brain temperature during $30 \mathrm{~min}$ exposure does not increase more than $1^{\circ} \mathrm{C}$ [5]. Although the exposure due to mobile phone use is below the admissible maximum values specified in the relevant standards, it is worth noting that a lot of mobile phone users report heating and sensation of warmth around the ear [6,7]. Also skin temperature measurements over the phone use area revealed elevated temperature. Experimental studies show that skin temperature in the area of the ear of a person using mobile phone increases by $2.3^{\circ} \mathrm{C}$ to $4.5^{\circ} \mathrm{C}$ (depending on mobile phone type) [8,9]. It remains to be seen whether the use of mobile phones leads to changes in the brain temperature. It is very important, because even subtle changes in tympanic temperature could influence the brain function. The studies on SAR and temperature in the head have so far been carried out only using thermal model of the head (phantom experiments) [10,11].
The aim of our experiment was to assess the tympanic temperature during exposure to EMF emitted by mobile phone in different conditions. Data on this problem are still sparse and incomplete.

\section{MATERIAL AND METHODS}

The volunteers taking part in the study were 10 young, healthy men aged 19-29 years, mean age 22.1 \pm 4.7 years. Their mean height was $179.5 \pm 5.8 \mathrm{~cm}$, mean weight $69.5 \pm 7.6 \mathrm{~kg}$ and body mass index (BMI) $21.5 \pm 1.53 \mathrm{~kg}$. The subjects gave their written informed consent to take part in the study and had a medical examination including otoscopic examination performed before the experiment. This has not revealed any abnormal findings. The study protocol was approved by the regional Biomedical Ethics Committee. The experiment was performed in wintertime, in laboratory, under strictly controlled climatic conditions: ambient temperature and relative humidity were maintained at $24^{\circ} \mathrm{C}$ and $70 \%$, respectively. The subjects were wearing a normalized, cotton clothes (long-sleeved shirt and trousers). The study was double-blind, randomized design.

Each subject participated in three sessions:

1. On a day without exposure $(2 \times 60 \mathrm{~min}$ of no exposure -2 hours in total, sham day - control conditions),

2. On a day with continuous exposure (60 min exposure and $60 \mathrm{~min}$ of no exposure - 2 hours in total),

3. On a day with intermittent exposure $(4 \times 15 \mathrm{~min}$ exposure - "on" and $4 \times 15$ min without exposure "off" -2 hours in total).

Detailed study protocol is displayed in Figure 1.

The subjects had not used a mobile phone for at least a week before each experimental day and they consented to the following study requirements: maintain a consistent and normal daily activities before the experiment; refrain from intake of alcohol and dietary supplementation of proteins and amino acids, avoid excessive physical exercise and sauna. 


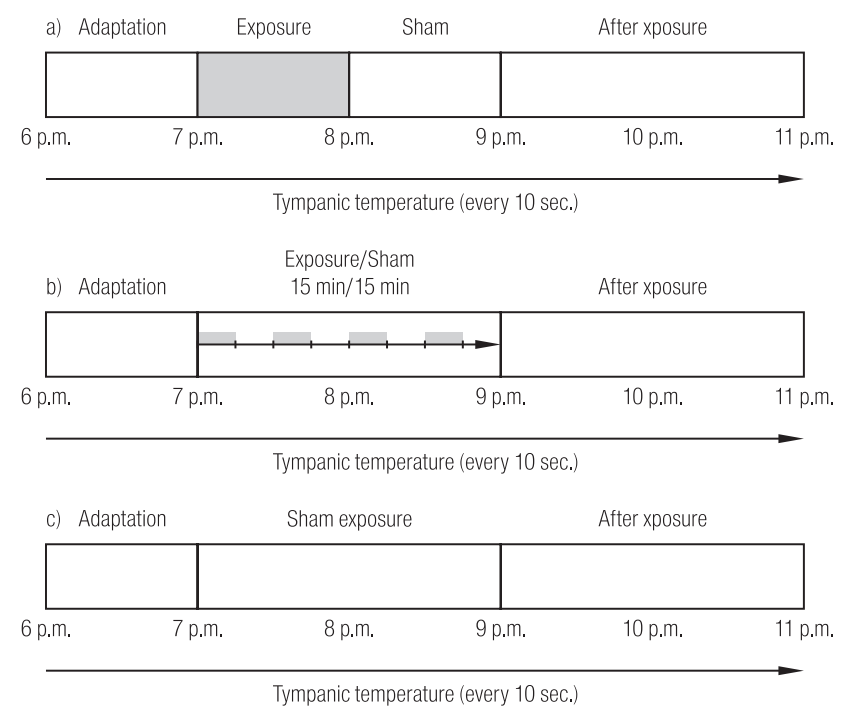

Fig. 1. Schedule of experiment (a - continuous exposure, $\mathrm{b}$ - intermittent exposure, $\mathrm{c}$ - sham day)

Since it was necessary to eliminate the influence of the possible stress caused by call on the physiological parameters, exposure consisted only in keeping the subject's head close to the mobile phone mounted on a stand (Figure 2). During sham day, the situation was the same, but mobile phone was off. The examined subjects did not know if mobile phone was "on" or "off". We used one standard mobile phone working with a frequency $900 \mathrm{MHz}$ ( $\mathrm{SAR}=1.23 \mathrm{~W} / \mathrm{kg}$ per $1 \mathrm{~g}$ tissue).

On the day of the experiment, the subjects entered the laboratory at 6 p.m. and stayed in sitting position till 7 p.m. Between 7 p.m. and 9 p.m. they were subjected to a real (continuous or intermittent) or sham exposure. Starting from 9 p.m. to 11 p.m. the subjects stayed at the sitting position and recovered while reading and listening to the music.

During the experiment the tympanic temperature $\left(\mathrm{T}_{\mathrm{ty}}\right)$, was monitored. Tympanic temperature was used as a measure of core temperature. Tympanic temperature was monitored to the nearest $0.01^{\circ} \mathrm{C}$ from 6 p.m. to 11 p.m. every 10 secs with a thermistor probe held in an external meatus with a soft coil spring (ST-21S, sensor Tecnica, Seto, Japan). Thermocouple (Shimadzu HK 7200) was

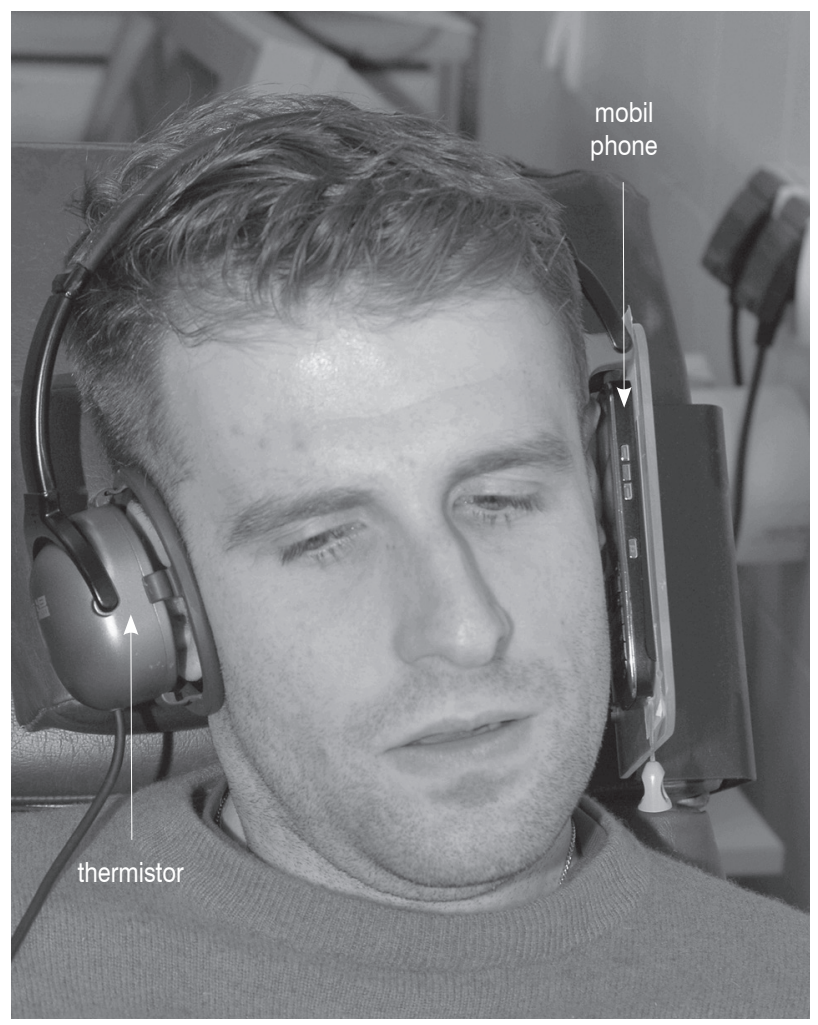

Fig. 2. Volunteer in experimental conditions

carefully inserted into the ear canal until it touched tympanic membrane according to the criteria [12]. The auditory canal was plugged with a piece of absorbent cotton to insulate it from the environment. Tympanic temperature was measured in the ear opposite the one in contact with mobile phone, to avoid electromagnetic interference of mobile phone with the thermocouple. Lack of electromagnetic disturbances was confirmed by examinations with phantom. The results of these experiments indicate that the tympanic thermometer meets the EMC requirements: its function is not affected by mobile phone EMF, provided that tympanic temperature is measured in the ear opposite the one in contact with the mobile phone.

During the experiment, blood pressure and heart rate were registered using a Medilog ABP (Oxford, England) every 5 min during exposure, every 15 min during recovery and every 30 min during sleep. Detailed data on blood pressure and heart rate were published earlier [13]. 


\section{STATISTICS}

Individual results of each subject were plotted in real time separately for different exposure conditions to reveal trends in individual reaction. Then the data was pooled for all group for each test condition. The statistical analysis was performed for the whole group referred to the following periods of experiment: during exposure (sham, continuous or intermittent) and after the exposure (two hours). We compared the tympanic temperature between day with continuous exposure or intermittent exposure and sham day separately for first and second hour of the exposure, and for first and second hour after exposure. Repeated-measures analysis of covariance was used to calculate the results of the experiment. The mean values of tympanic temperature before the experiment were the covariate in the model. Multiple comparison Sidak test for comparing mean tympanic temperature in each hour between sham vs. continuous and sham vs. intermittent exposure was used. For all the statistical tests used, the level of significance was $\alpha=0.05$.

\section{RESULTS}

The mean tympanic temperature in the whole group during the continuous exposure was significantly higher than on the sham day $(\mathrm{p}=0.001)$, this difference amounted to $0.02^{\circ} \mathrm{C}$. Within an hour after exposure, the mean tympanic temperature was higher by $0.03^{\circ} \mathrm{C}$. Two hours after continuous exposure, tympanic temperature was lower than after sham exposure $\left(0.06^{\circ} \mathrm{C}\right)$.

During intermittent exposure, the temperature was lower than during sham day (difference was up to $0.11^{\circ}$ ). Within an hour after exposure, the mean tympanic temperature was lower by $0.18^{\circ} \mathrm{C}$, two hours after intermittent exposure the temperature was also lower and the difference was significant $\left(0.26^{\circ} \mathrm{C}, \mathrm{p}=0.0001\right)$. The changes of the tympanic temperature in the study group (raw data) are

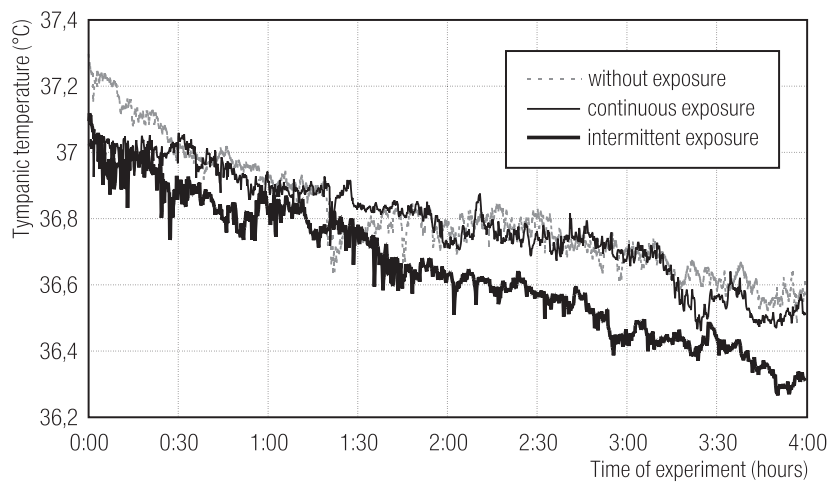

Fig. 3. Real time values of tympanic temperature in relation to exposure conditions (mean values for whole group - raw data)

presented in Figure 3. The trends in $\mathrm{T}_{\mathrm{ty}}$ during the experiment differed significantly in relation to exposure conditions $(\mathrm{p}<0.05)$.

To find out whether the type of exposure may affect the tympanic temperature, the trend of changes in temperature for the continuous and intermittent exposure was compared with respective findings on the sham day (Table 1). Since the temperature measured before the experiment might affect the temperature during all exposure types, it was considered as a covariance. The adjusted tympanic temperatures for group on the day of continuous and intermittent exposure were found to differ significantly from

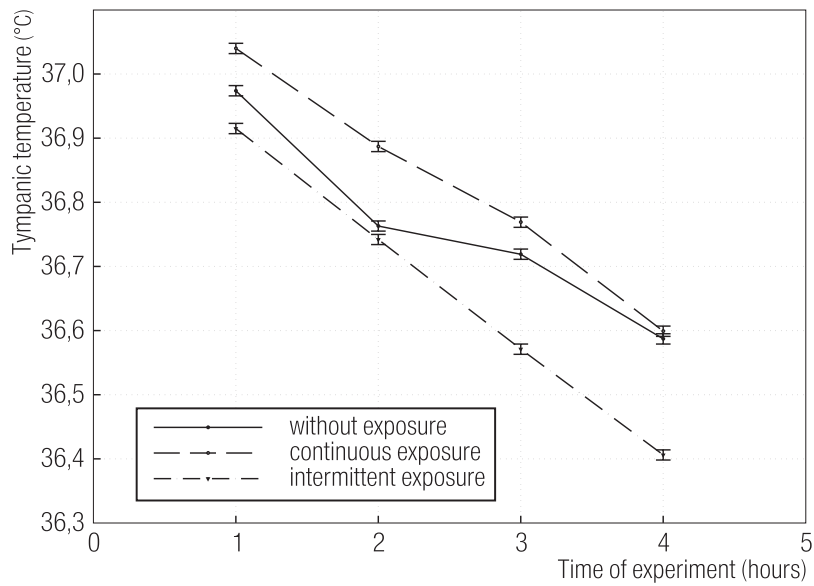

Fig. 4. Tympanic temperature in relation to exposure conditions (adjusted for temperature before the experiment: mean values and $95 \%$ confidence intervals for whole group) 
Table 1. Pairwise comparisons between mean values of tympanic temperature during exposure and sham day

\begin{tabular}{llccr}
\hline $\begin{array}{c}\text { Time of experiment } \\
\text { (hour) }\end{array}$ & Exposure conditions & $\begin{array}{c}\text { Mean difference in } \\
\text { temperature }\left({ }^{\circ} \mathrm{C}\right)\end{array}$ & Standard error & $\mathrm{p}$ \\
\hline 1 & continuous vs. sham & -0.067 & 0.006 & $<0.0001$ \\
& intermittent vs. sham & 0.058 & 0.006 & $<0.0001$ \\
2 & continuous vs. sham & -0.124 & 0.006 & $<0.0001$ \\
& intermittent vs. sham & 0.021 & 0.006 & 0.0010 \\
3 & continuous vs. sham & -0.050 & 0.006 & $<0.0001$ \\
& intermittent vs. sham & 0.148 & 0.006 & $<0.0001$ \\
4 & continuous vs. sham & -0.012 & 0.006 & 0.1090 \\
& intermittent vs. sham & 0.181 & 0.006 & $<0.0001$ \\
\hline
\end{tabular}

the temperatures recorded during respective time periods of the sham day (Figure 4).

The results of this analysis indicate that the physiological response to EMF exposure from mobile phone was mostly related to the type of exposure (continuous or intermittent). It is worth noting that after last hour of experiment with continuous exposure and with sham exposure, the tympanic temperature did not differ significantly, opposite to intermittent exposure, when tympanic temperature all time was significantly lower than during sham exposure.

\section{DISCUSSION}

The findings of our study revealed that the level of tympanic temperature decreased in the course of the experiment according to the circadian rhythm of temperature variations. However, changes in the temperature were different in particular days of experiment. This effect was significantly related to the kind (continuous or intermittent) of exposure. Different response during and after continuous and intermittent exposure was observed also for blood pressure [13].

We found the tympanic temperature to increase during continuous exposure. This effect was not so evident as in phantom experiments performed by other authors, who reported temperature increases ranging from $0.08^{\circ} \mathrm{C}$ to $0.16^{\circ} \mathrm{C}$. However, those authors did not consider the role of the thermoregulatory system, which may significantly affect the actual temperature of the brain [10,11,14]. The decrease in the tympanic temperature we noted during intermittent exposure may be surprising, as it would seem more reasonable to expect increased temperature levels. One explanation of our results is that the heating of the blood flowing through the brain area, induced by EMF exposure, may lead to set-point changes, activation of the thermoregulatory system and consequently to a decrease in tympanic temperature. Another possible explanation is the direct stimulation of the thermoregulatory system by electromagnetic waves. Both mechanisms are plausible; however, up to date, no relevant literature reports are accessible.

Human experimental studies performed thus far have revealed subtle thermophysiological changes during exposure to radiofrequency EMF [15,16]. However, those results cannot be compared with our findings due to different exposure conditions (whole body vs. head), different operating frequency of EMF exposure system (450 and $2450 \mathrm{MHz}$ vs. $900 \mathrm{MHz}$ ) and site of measurement of the core temperature (esophageal vs. tympanic). Considering the possible health effects of exposure to mobile phone EMF, it is worth noting that the changes in brain temperature occurring during and after exposure may have physiological consequences and partially explain the symptoms reported by mobile phone users. Changes in 
arterial blood pressure may explain the sleep disturbances reported by mobile phone users [17].

Further research is necessary to investigate the mechanism of EMF action on human brain in view of the theoretical possibility that the changes in the tympanic temperature may contribute to impairments in brain functioning, for example there are experimental data on EMF-induced changes in the permeability of the blood-brain barrier. This effect was significantly related to exposure parameters (EMF frequency and SAR) as well as the substance for which the permeability was determined $[18,19]$.

\section{REFERENCES}

1. Repacholi MH. Low level exposure to radiofrequency electromagnetic fields: health effects and research needs. Bioelectromagnetics 1998;19(1):1-19.

2. Sandstrom M, Wilen J, Oftedal G, Mild H. Mobile phone use and subjective symptoms. Comparison of symptoms experienced by users of analogue and digital mobile phones. Occup Med 2001;51(1):25-35.

3. Taurisano MD, Vorsa AV. Experimental Thermographic Analysis of Thermal Effects Induced on a Human Head Exposed to 900-MHz Fields of Mobile Phones. IEEE Trans Microwave Theory Tech 2000;48:2022-32.

4. ICNIRP Guidelines for limiting exposure to time-varying electric, magnetic and electromagnetic fields (up to $300 \mathrm{GHz}$ ). Health Phys 1998;74(4):494-522.

5. International Commission on Non-Ionizing Radiation Protection. Health issues related to the use of hand-held radiotelephones and base transmitters. Health Phys 1996;70(4):587-93.

6. Hocking B. Preliminary report: symptoms associated with mobile phone use. Occup Med 1998;48(6):357-60.

7. Oftedal G, Wilen J, Sandstrom M, Mild KH. Symptoms experienced in connection with mobile phone. Occup Med 2000;50(4):237-45.

8. Anderson V, Rowley J. Measurements of skin surface temperature during mobile phone use. Bioelectromagnetics 2007;28(2):59-62.
9. Straume A, Oftedal G, Johnsson A. Skin temperature increase caused by a mobile phone: a methodological infrared camera study. Bioelectormagnetics 2005;26(6):510-9.

10. Bernardi P, Cavagnaro M, Pisa S, Piuzzi E. Specific $A b$ sorption Rate and Temperature Increases in the Head of a Cellular-Phone User. IEEE Trans. Microwave Theory Tech 2000;48:1118-25.

11. Wainwright $\mathrm{P}$. Thermal effects of radiation from cellular telephones. Phys Med Biol 2000;45(8):2363-72.

12. Brinnell $\mathrm{H}$, Cabanac M. Tympanic temperature is a core temperature in humans. J Therm Biol 1989;14(1):47-53.

13. Bortkiewicz A, Gadzicka E, Szymczak W. Physiological response to experimental exposure to electromagnetic fields emitted by mobile phone. In: Holmer I, Kuklane K, Gao Ch, editors. Environmental Ergonomics Vol. XI. Ystad: Lund University; 2005. p. 620-3.

14. Dimbylow PJ, Mann SM. SAR calculations in an anatomically realistic model of the head for mobile communication transceivers at $900 \mathrm{MHz}$ and $1.8 \mathrm{GHz}$. Phys Med Biol 1994;39(10):1537-53.

15. Adair ER, Kelleher SA, Mack GW, Morocco TS. Thermophysiological Responses of Human Volunteers During Controlled Whole-Body Radio-Frequency Exposure at $450 \mathrm{MHz}$. Bioelectromagnetics 1998;19(4):232-45.

16. Adair ER, Cobb BL, Mylacraine KS, Kelleher SA. Human Exposure at Two Radio-Frequencies (450 and $2450 \mathrm{MHz}$ ): Similarities and Differences in Physiological Response. Bioelectromagnetics 1999; Suppl 4:12-20.

17. Mann K, Roschke J. Effects of pulsed high frequency electromagnetic fields on human sleep. Neuropsychobiology 1996;33(1):41-7.

18. Fritze K, Sommer G, Schmitz B, Mies G, Hossmann KA, Kiessling M, et al. Effect of global system for mobile communication (GSM) microwave exposure on blood-brain permeability in rat. Acta Neuropathol 1997;94(5):465-70.

19. Salford LG, Brun A, Sturesson K, Eberhard JL, Person BR. Permeability of the blood-brain barrier induced by $915 \mathrm{MHz}$ electromagnetic radiation, continuous wave and modulated at 8, 16, 50 and 200 Hz. Micros Res Tech. 1994;27(6):535-42.

This work is available in Open Access model and licensed under a Creative Commons Attribution-NonCommercial 3.0 Poland License - http://creativecommons.org/ licenses/by-nc/3.0/pl/deed.en. 